\title{
Effects of Surface Treatments of Montmorillonite Nanoclay on Cure Behavior of Diglycidyl Ether of Bisphenol A Epoxy Resin
}

\author{
Alfred Tcherbi-Narteh, Mahesh V. Hosur, Eldon Triggs, and Shaik Jelaani \\ Department of Material Science Engineering, Tuskegee University, Tuskegee, AL 36088, USA \\ Correspondence should be addressed to Mahesh V. Hosur; hosur@mytu.tuskegee.edu
}

Received 1 May 2013; Revised 15 October 2013; Accepted 27 October 2013

Academic Editor: Yeong Suk Choi

Copyright (c) 2013 Alfred Tcherbi-Narteh et al. This is an open access article distributed under the Creative Commons Attribution License, which permits unrestricted use, distribution, and reproduction in any medium, provided the original work is properly cited.

Diglycidyl ether of Bisphenol A (DGEBA) based SC-15 epoxy resin was modified with three different commercially available montmorillonite (MMT) nanoclay: Nanomer I.28E and Cloisite 10A and 30B. Cure behavior of nanocomposites was studied using a variety of techniques. Primary focus of this study was to investigate influence of different surface modifications of MMT nanoclay on rheological properties and cure behavior of SC-15 epoxy resin. By adding MMT to SC-15 epoxy resin, chemistry of the epoxy is altered leading to changes in rheological properties and ultimately enthalpy and activation energy of reactions. Addition of Nanomer I.28E delayed gelation, while Cloisite $10 \mathrm{~A}$ and $30 \mathrm{~B}$ accelerated gelation, regardless of the curing temperature. Activation energy of reaction was lower with the addition of Nanomer I.28E and Cloisite 10A and higher for Cloisite 30B compared to neat SC-15 epoxy composite.

\section{Introduction}

Thermosetting epoxy resins are widely used across many industries in a variety of applications such as in paint and coating industries, adhesives, and as matrices for composite laminates due to exceptional properties [1-4]. These properties are further enhanced by modifying resins with small amounts of fillers such as nanoparticles. In this process, chemistry of the polymer systems is altered and consequently affects their processing. Properties of most polymeric composites depend on processing parameters including curing temperature and time to a great extent, leading to formation of network of polymer chains. However, in reinforced polymer composites, properties are mostly dictated by the interfacial chemistry and subsequent interaction between filler materials and polymers molecules along with the aforementioned factors. Among many commercially available nanoparticles used as fillers in epoxy resins, nanoclay stands out as the one with an ability to improve mechanical and thermal properties [4-6]. MMT also exhibits good barrier properties against moisture and volatiles during decomposition based on their unique morphology $[7,8]$. One such nanoclay is naturally occurring $2: 1$ phyllosilicate montmorillonite clay which in the natural form is hydrophilic and incompatible with most polymers. Hence, surface of most commercially available nanoclay used as fillers is modified using organic modifiers to overcome these challenges leading to the formation of miscible solutions $[9,10]$. Surface modifications also help to reduce tendency of clay agglomeration during dispersion by reducing interlayer attractive forces between the platelets thereby enhancing dispersion [6]. Other studies $[11,12]$ have shown that presence of MMT facilitates ring opening polymerization in most epoxy polymers by readily reacting with epoxide ring affecting the rate of chemical reaction.

Generally, nanoclay infusions into polymer result in flocculated, intercalated, or exfoliated morphologies, each with diverse potential to influence the polymer chain network structure and overall properties $[3,13]$. During processing, silicate layers in an epoxy mixture can orient along with the mesoscale structure, and this ability dictates linear viscoelastic properties of the mixture [13]. In highly exfoliated systems, nanoclay particles orientation results in the formation of anisotropic solutions increasing viscosity and surface 


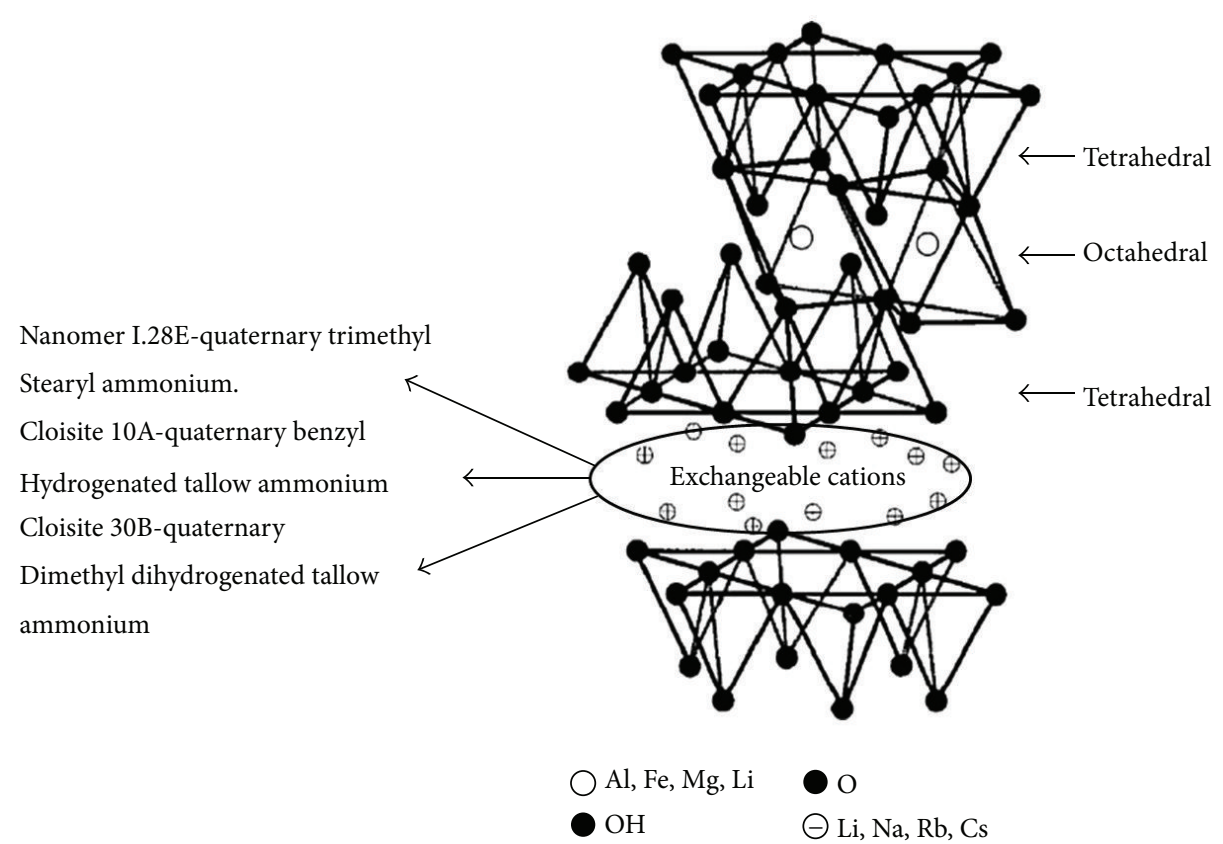

FIgURE 1: Chemical structure of montmorillonite nanoclay [3].

interactions [12-15]. Interactions between nanoclay particles and epoxy molecules affect the viscosity and mobility of reacting species during curing. Consequently this influences rate of cure, reaction time, enthalpy, vitrification, activation energy, viscoelastic properties, and crosslinking density of the final composite $[9,12,16,17]$. Other factors such as type and amount of clay fillers and organic modifiers and their interaction with the intended host polymer molecules and their curing agents have all shown to influence properties of polymeric composites during processing $[12-14,17,18]$.

Cure kinetic parameters including activation energy depend on constituents of polymeric systems; therefore modified polymer systems may require different set of processing parameters in order to optimize their properties other than that recommended by manufacturers. Gelation is critical in thermoset processing as it defines the most distinguishing characteristic of liquid epoxy and its use as matrix system for the fabrication of laminated composites. Beyond gel point epoxy processing becomes almost impossible due to onset of crosslinking coupled with rapid increase in the viscosity. Therefore understanding influence of surface modifications in nanoclay fillers on rheological properties of polymers is critical as it directly relates to consistency in flow during processing and development of material properties in nanocomposites.

In the current study, influence of three different organically modified montmorillonite nanoclays on rheological properties and cure behavior of DGEBA epoxy resin SC15 was investigated. Nanomer I.28E and Cloisite 10A and 30B with different surface modifications were used and cure kinetic parameters were evaluated using isothermal rheological studies.

\section{Experimentation}

2.1. Materials. Commercially available two part (A and B) SC-15 epoxy resin system was used for this study. SC-15, a DGEBA epoxy system with low shrinkage and relatively high thermal stability, was obtained from Applied Poleramic Inc. The curing agent (part B) is a cycloaliphatic amine hardener. The epoxy resin system was modified with three commercially available montmorillonite nanoclays (MMT): Nanomer I.28E from Sigma Aldrich and Cloisite 10A and Cloisite 30B from Southern Clay Inc. The MMT used is naturally occurring 2:1 layered smectite clay mineral with typical chemical structure shown in Figure 1 and chemical composition of $\mathrm{A}_{0.3}\left(\mathrm{Al}_{1.3} \mathrm{Mg}_{0.7}\right)\left[\mathrm{Si}_{4}\right] \mathrm{O}_{10} \cdot(\mathrm{OH})_{2} \cdot x \mathrm{H}_{2} \mathrm{O}$, where " $\mathrm{A}$ " is exchangeable cation, $\mathrm{K}^{+}, \mathrm{Na}^{+}$, or $0.5 \mathrm{Ca}^{2+}$. Particle size distribution of clustered MMT clays was between 8 and $12 \mu \mathrm{m}$. Surface of Nanomer I.28E is modified with 25$30 \mathrm{wt} . \%$ of quaternary trimethyl stearyl ammonium with CEC of $93.7 \mathrm{meq} / 100 \mathrm{~g}$, while Cloisite $10 \mathrm{~A}$ and $30 \mathrm{~B}$ are modified with quaternary dimethyl, benzyl, hydrogenated tallow ammonium, and quaternary dimethyl dihydrogenated tallow ammonium with CEC of $125 \mathrm{meq} / 100 \mathrm{~g}$ and $90 \mathrm{meq} / 100 \mathrm{~g}$, respectively. Specific details about surface modifications are proprietary. Therefore, aim of this study is to investigate what influence a particular commercially available nanoclay will have on the cure behavior of an epoxy resin system without going into the details of the interactions between polymer and nanoclays.

2.2. Sample Preparation. Each MMT used in the study was dried in a convection oven for 2 hours, allowed to cool, and then thoroughly dispersed into measured amount of SC-15 
in a beaker to form 2 wt.\% MMT-epoxy composite using magnetic stirring technique. Two wt.\% was chosen based on our previous studies wherein it gave most enhancement in the properties. Stoichiometric amount of SC-15 hardener (part B) was then added at a ratio of 100 part A : 30 part B by weight and stirred mechanically followed by desiccation to get rid of any bubbles. Rheological and cure kinetic studies were conducted using small amount of uncured neat and modified SC-15 epoxy resin mixture to determine the cure kinetic parameters. Part of each mixture was poured into molds and cured at ambient temperature for $24 \mathrm{~h}$ followed by $2 \mathrm{~h}$ after curing at $100^{\circ} \mathrm{C}$ to form epoxy composite samples.

\subsection{Characterization}

2.3.1. Rheological. Influence of MMT clay type on rheological behavior of SC-15 was studied using TA Instruments (Delaware) AR 2000 rheology equipment with $25 \mathrm{~mm}$ parallel ETC steel plates. Shear experiments were performed on unmodified and modified SC-15 at shear rates varying from 0 to $100 \mathrm{rads}^{-1}$ and compared. Rheological measurements were carried out in ambient temperature with oscillatory maximum normal force of $0.50 \mathrm{~N}$. Nanoclay effects on viscosity and subsequent developments of viscoelastic properties of SC-15/MMT during curing were also studied using isothermal rheology, where the rheological equipment was operated in oscillation-time-sweep mode at $60,70,80$, and $90^{\circ} \mathrm{C}$. Evolution of storage modulus $\left(G^{\prime}\right)$ and loss modulus $\left(G^{\prime \prime}\right)$ was monitored as function of reaction time. Test results were analyzed using TA Instruments "Data Analysis" software.

2.3.2. Differential Scanning Calorimetry (DSC). Effect of different MMT clays on cure behavior of modified epoxy resin was investigated by conventional differential scanning calorimetry (DSC) using Q1000 equipment from TA Instruments Inc. The instrument was purged with nitrogen gas at a flow rate of $50 \mathrm{~mL} / \mathrm{min}$ during scanning. Cell constant and temperature sensitivity of the DSC equipment were calibrated using sapphire samples and indium metal, respectively. Aluminum hermetic pans were used as reference and sample pans. Dynamic scans were performed at scanning rates of 2.5, $5.0,10.0$, and $15.0^{\circ} \mathrm{C} / \mathrm{min}$ from 30 to $240^{\circ} \mathrm{C}$ while isothermal scans were carried out at $60,70,80$, and $90^{\circ} \mathrm{C}$ over a period of 320 minutes. Sample weights were maintained between 8 and $10 \mathrm{mg}$ for both dynamic and isothermal scans for consistency and minimization of heat gradient. Heat flux was recorded as a function of temperature for dynamic scanning and time for isothermal scanning, up to a point where there was no noticeable changes in the heat flow compared to baseline data. Results from DSC scans were analyzed using TA Instruments' Specialty Library.

2.4. Cure Reaction. Chemical reactions involved in curing of epoxies can be complex based on the composition and may take various forms; however, degree of cure can be related to heat released during curing at any given temperature. Thus, rate of cure $(d \alpha / d t)$ of any given chemical reaction in a DSC experiment is directly proportional to the measured heat flow rate $(d H / d t)$ relative to the baseline of the instrument and can be expressed as

$$
\frac{d \alpha}{d t}=\frac{d H / d t}{\Delta H}
$$

where $\Delta H$ is the total heat generated from the reaction to reach full conversion (enthalpy). Furthermore, reaction mechanism can be analyzed as function of conversion fraction $(\alpha)$ and temperature $(T)$ which is expressed as

$$
\frac{d \alpha}{d t}=K(T) f(\alpha)
$$

where $f(\alpha)$ is a time- and temperature-dependant function and $K(T)$ is a temperature-dependant function and expressed in Arrhenius form as

$$
K(T)=A \exp \left(-\frac{E_{a}}{R T}\right),
$$

where $A$ is the preexponential factor, $E_{a}$ is apparent activation energy, $R$ is the universal gas constant $(8.3144 \mathrm{KJ} / \mathrm{mol})$, and $T$ is the absolute temperature $(\mathrm{K})$. Thus, maximum reaction rate $(d \alpha / d t)$ occurs at the peak temperature $\left(T_{p}\right)$ and can be expressed as

$$
\frac{d \alpha}{d t}=A e^{\left(-E_{a} / R T_{p}\right)} \cdot f(\alpha) .
$$

Introducing the heating rate $\beta$, which can be expressed as $d T / d t$, (3) can further be expressed as

$$
\frac{d \alpha}{d T}=\frac{A}{\beta} e^{\left(-E_{a} / R T_{p}\right)} \cdot f(\alpha) .
$$

Taking logarithm of both sides and rearranging terms, activation energy $\left(E_{a}\right)$ can be obtained from the slope of plots of $\ln (\beta)$ versus $1 / T_{p}$ according to ASTM E698 [19] utilizing Ozawa method and can be expressed in as

$$
E_{a}=\frac{R}{1.052} \cdot \frac{d \ln \beta}{d\left(1 / T_{p}\right)} .
$$

Cure reaction of unmodified and modified epoxy network was characterized using the same technique, where heat of reaction $\Delta H$, activation energy $E_{a}$, preexponential factor were determined and compared with that of the neat system.

2.5. Morphological. Microstructural analyses performed on cured samples using X-ray diffraction techniques (XRD) and transmission electron microscopy (TEM) were used to establish degree of dispersion in each sample. Intergallery spacing between clay platelets was determined for powdered nanoclay and their respective nanocomposites samples for comparison using Bragg's law. XRD study was done using Rigaku-DMAX-2000 equipped with $\mathrm{Cu} \mathrm{K \alpha}$ radiation of wavelength $\lambda=1.54 \mathrm{~nm}$, operating at $40 \mathrm{KV}$ and $30 \mathrm{~A}$, and samples were scanned at $0.2^{\circ}$ from $2 \vartheta$ values of $2-$ $40^{\circ}$. High resolution TEM studies were performed on each nanocomposite to further establish MMT dispersion in each SC-15 nanocomposite. TEM samples were microtomed from each cured epoxy nanocomposite, collected in a water bath, and transferred onto $200 \mathrm{Cu}$ mesh and scanned. 
TABLE 1: Dependency of viscosity on shear rate.

\begin{tabular}{lcccc}
\hline \multirow{2}{*}{ Sample/shear rate, 1/s } & \multicolumn{2}{c}{ Viscosity at various shear rates, $\mu$ Pa.s } \\
& Neat SC-15 & SC-15/Nanomer I.28E & SC-15/Cloisite 10A & SC-15/Cloisite 30B \\
\hline 1 & $512.50 \pm 14.13$ & $855.73 \pm 32.67$ & $3335.61 \pm 345.06$ & $1083.55 \pm 223.45$ \\
5 & $723.33 \pm 29.66$ & $764.37 \pm 11.16$ & $2774.45 \pm 620.20$ & $1500.00 \pm 147.00$ \\
8 & $1291.00 \pm 37.56$ & $1248.67 \pm 21.85$ & $4073.59 \pm 594.78$ & $2336.50 \pm 250.50$ \\
10 & $820.80 \pm 35.20$ & $839.67 \pm 11.70$ & $2654.34 \pm 61.96$ & $1351.50 \pm 99.50$ \\
20 & $628.73 \pm 23.31$ & $614.73 \pm 12.39$ & $1768.02 \pm 72.31$ & $1042.40 \pm 73.60$ \\
100 & $489.53 \pm 16.04$ & $467.53 \pm 11.92$ & $1335.22 \pm 77.10$ & $859.05 \pm 26.85$ \\
\hline
\end{tabular}

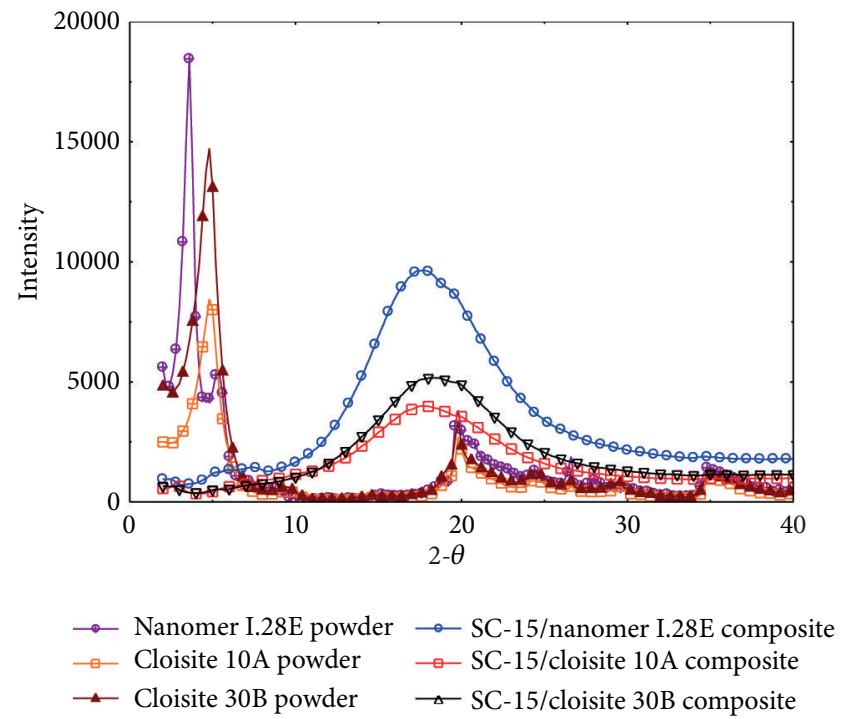

FIGURE 2: XRD diffraction peaks of Nanomer I.28E, Cloisite 10A and $30 \mathrm{~B}$ clay samples, and their respective composites.

\section{Results and Discussion}

3.1. Morphological Studies. Property enhancements involving nanoclays have been attributed to degree of dispersion, ability of host polymer molecules to percolate and expose large surface area of nanoclay to enhance interactions. Interactions of these high aspect ratio particles with epoxy molecules govern most chemical reactions and subsequent enrichments in properties. Prominent diffraction peaks indicative of highly organized clay platelets in each clay sample were observed at $2 \theta$ values of $3.60,4.88$, and $4.80^{\circ}$ for Nanomer I.28E and Cloisite $10 \mathrm{~A}$ and $30 \mathrm{~B}$, respectively, (Figure 2). Subsequent diffraction peaks from their respective nanocomposites showed broader peaks with lower intensities and at higher $2 \theta$ values between 17.50 and $18.50^{\circ}$. Variation in diffraction peaks can be attributed to different surfactant used in their respective surface modifications and interaction with SC-15 epoxy molecules. Intergallery $d$-spacing determined using Bragg's law for each type of nanoclay was 7.91, 11.93, and $11.40 \AA$ for Nanomer I.28E and Cloisite 10A and 30B, respectively, while that of their corresponding nanocomposites was $13.2,27.2$, and $24.4 \AA$. The results showed an increase of about 67,127 , and $114 \%$ in $d$-spacing between powdered clay and their respective composites. Increasing lattice space between the clay platelets suggests intercalation of epoxy molecules into the intergallery of the clay particles by percolating into clay platelets and moveing them apart. This phenomenon depends on factors such as clay surface morphology, dispersion time, curing agents, and curing temperature $[11,14,16$, 19, 20]. These results also illustrate chemical compatibility between quaternary benzyl hydrogenated tallow ammonium surfactant used in Cloisite 10A modification and SC-15 epoxy molecules. This was demonstrated by the ability of the Cloisite 10A clay to allow epoxy molecules to percolate into the intergallery and move them farthest apart compared to other nanocomposites as can be seen from increased $d$ spacing. This study revealed that more epoxy molecules intercalated into Cloisite 10A followed by Cloisite 30B and finally Nanomer I.28E based on the intensities of XRD observed in their respective nanocomposites.

Further morphological studies were done to qualitatively establish degree of clay dispersion in their respective nanocomposites using transmission electron microscope (TEM). TEM micrographs obtained at different locations from various nanocomposite surfaces are shown in Figure 3. Intercalated morphologies were prevalent in all samples as seen from micrographs obtained from samples used in the current study, possibly due to ambient curing condition and insufficient dispersion time. Microstructural analyses indicated that, due to different surface modifications, percolation and interaction of clay particles and epoxy molecules were diverse, as shown by different $d$-spacing values in their respective nanocomposites.

\subsection{Rheological Studies}

3.2.1. Viscosity Dependency on Shear Rate. Experimental plots of viscosity of uncured neat and MMT modified SC15 epoxy systems in ambient temperature are presented in Figure 4 and average values presented in Table 1 for comparison. At low shear rate, influence of different surface modifications in montmorillonite clay became apparent as viscosity varied for various MMT infused samples. Initial response in viscosity to applied shear stress significantly varied from one system to the other mainly due to interaction between clay and epoxy molecules. These interactions in conjunction with that between the nanoclay particles within the epoxy in response to applied stress led to higher viscosity measurements at low shear rate $\left(0-5 \mathrm{~s}^{-1}\right)$ compared to neat SC-15 system $[14,21]$. Low shear rate further allowed epoxy 


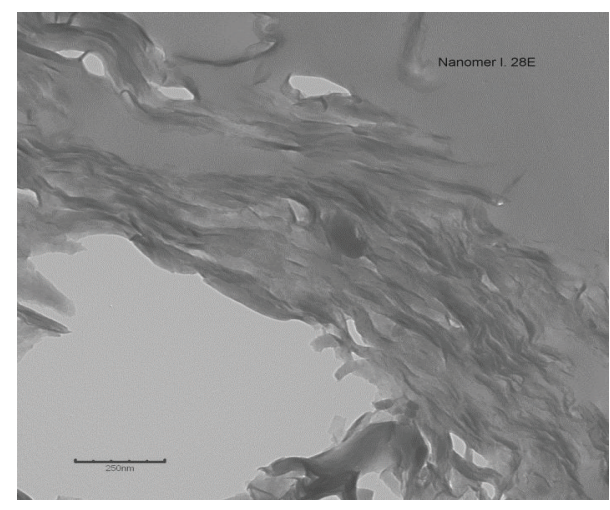

(a)

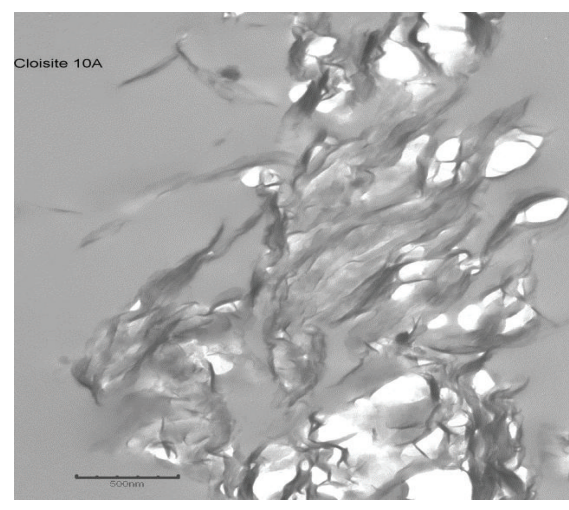

(b)

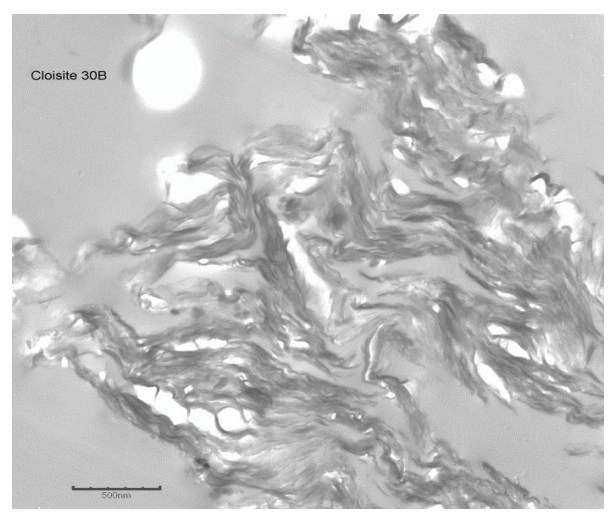

(c)

FIGURE 3: TEM micrographs of SC-15 nanocomposites infused with (a) Nanomer I.28E and (b) Cloisite 10A and (c) Cloisite 30B.

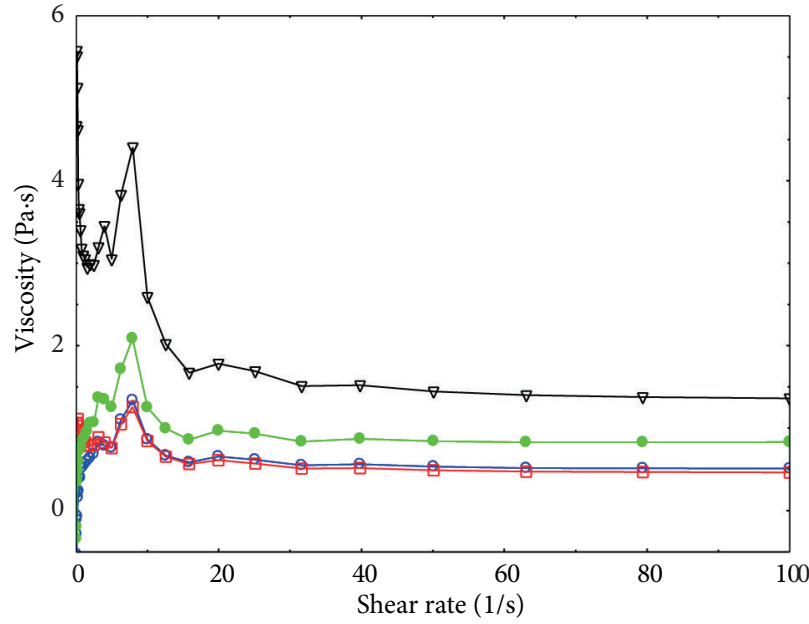

$\rightarrow$ SC-15 epoxy $\rightarrow$ SC-15/Cloisite 10A

$\rightarrow$ SC-15/Nanomer I.28E $\rightarrow$ SC-15/Cloisite 30B

(a)

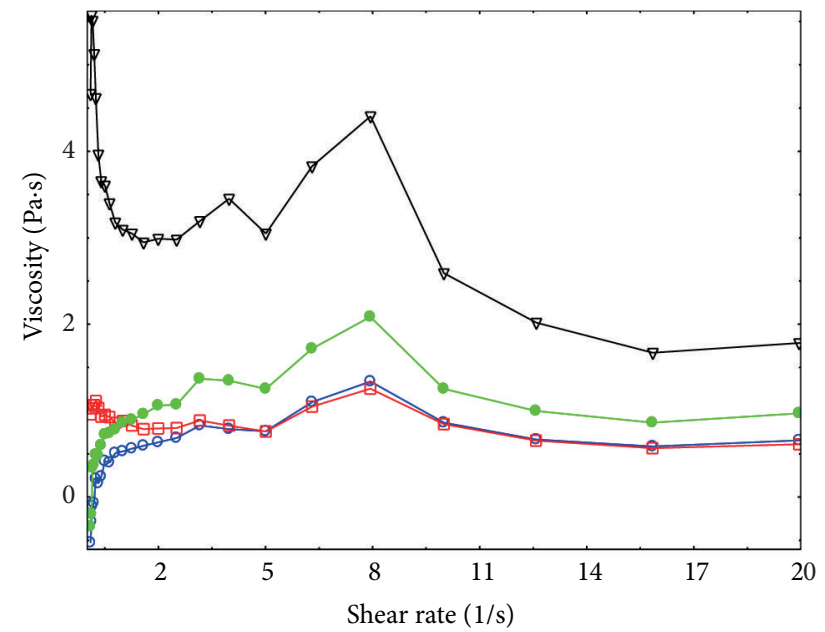

$\rightarrow$ SC-15 epoxy $\rightarrow$ SC-15/Cloisite $10 \mathrm{~A}$
$\rightarrow$ SC-15/Nanomer I.28E $\rightarrow$ SC-15/Cloisite 30B

(b)

FIGURE 4: Influence of different MMTs on rheological properties at room temperature at (a) shear rates from 0 to $100 \mathrm{~s}^{-1}$ and (b) from 0 to $20 \mathrm{~s}^{-1}$ heating rate: $10^{\circ} \mathrm{C} / \mathrm{min}$. 
TABLE 2: Summary of isothermal rheology.

\begin{tabular}{lcccc}
\hline Sample & Cure temperature, ${ }^{\circ} \mathrm{C}$ & Gel time, $s$ & Storage modulus, at gel point, Pa & Viscosity at gel point, Pa·s \\
\hline \multirow{3}{*}{ SC-15 composite } & 60 & 3451 & 43810 & 9844 \\
& 70 & 1801 & 30380 & 6882 \\
& 80 & 1001 & 4884 & 2977 \\
& 90 & 391 & 9806 & 22570 \\
SC-15/Nanomer I.28E & 60 & 5851 & 28260 & 6109 \\
& 70 & 3131 & 12010 & 2138 \\
& 80 & 1491 & 4767 & 1073 \\
SC-15/Cloisite 10A & 90 & 841 & 92680 & 20820 \\
& 60 & 3007 & 27690 & 6197 \\
& 70 & 1616 & 10400 & 2352 \\
SC-15/Cloisite 30B & 80 & 646 & 7761 & 1743 \\
& 90 & 474 & 58920 & 13280 \\
& 60 & 3275 & 28650 & 6451 \\
& 70 & 1597 & 7166 & 1663 \\
& 80 & 566 & 6374 & 1378 \\
\hline
\end{tabular}

molecules to percolate between layers of clay platelets causing swelling and increase of intergallery spacing. This process is controlled among other things by temperature, interfacial chemistry of clay surface, particle-particle interactions, $\mathrm{pH}$ of the system, and host polymer molecules leading to changes in rheological behavior [22, 23].

As shear rate increased from 8 to $20 \mathrm{~s}^{-1}$, percolation time and orientation of clay platelets in each mixture in response to applied shear stress varied due to the presence of different organic modifiers in each composition $[9,12,14,15]$. This effect can be seen in viscosity measurements of each sample shown in Figure 4(b). However, behavior of all MMT modified SC-15 systems in response to increasing shear stress beyond $20 \mathrm{~s}^{-1}$ was identical to that of neat system. This behavior was possibly due to inadequate time for epoxy molecules to move further into the clay layers forming a mesoscopic mixture in response to increasing shear rate. Hence all systems behaved indistinguishably regardless of clay surface modifications. Identical rheological behavior with varying viscosities demonstrates dependence of viscosity on particleparticle and particle-host interactions as studies have shown [9-13]. Also, behavior of all systems at shear rates of 5, 8, and $20 \mathrm{~s}^{-1}$ can be characteristic of SC-15 epoxy system in response to applied stress $[12,21]$. Overall, viscosity of samples with Cloisite 10A showed higher values throughout the study compared to other nanocomposites including neat system as shown in Figure 4(b). Higher values of viscosity observed in SC-15/Cloisite 10A samples are indicative of anisotropic microstructural behavior where epoxy molecules moved into the intergallery spacing and cause the clay layers to swell and move further apart [12-15]. It also demonstrates better interaction between epoxy molecules and quaternary benzyl hydrogenated tallow ammonium salt between clay layers allowing percolation and causing swelling. This phenomenon can lead to complete separation of clay platelets to form anisotropic solution leading to higher viscosity $[14,15]$. It is therefore safe to assume that, among various MMT compositions used in this study, SC-15/Cloisite 10A mixture showed relatively better dispersion. This assertion can be corroborated by results from XRD studies showing relative lower intensity and broader diffraction peaks and highest percent change in $d$-spacing between clay platelets in SC-15/Cloisite $10 \mathrm{~A}$ samples (Figure 2). Furthermore, with extended dispersion time, we speculate that SC-15/Cloisite 10A clay platelets may move even farther apart enhancing dispersion and affect viscosity and final properties of composites as suggested by several studies [11, 24, 25]. In this work, at the end of the study, viscosity of Cloisite 10A and Cloisite 30B infused SC-15 resin increased by about $173 \%$ and $76 \%$, respectively, while Nanomer I.28E decreased by nearly 5\%. This shows that although identical behavior was observed beyond $20 \mathrm{~s}^{-1}$, clearly organic modifiers significantly influenced viscosity of the host polymer which may affect processability and curing leading to different property development.

3.2.2. Isothermal Rheological Studies. Generally, curing of epoxy resin with amino curing agents involves reactions of primary and secondary amine with epoxide molecules and a reaction between hydroxyl by-product and epoxide to form ether molecules (etherification) resulting in branching and crosslinking [26-28]. Kinetic model for these reactions can either be $n$th order or autocatalytic. However, studies have shown that most epoxy resin cure reactions are autocatalytic in nature $[16,17,27,29]$. During curing, low viscosity SC15 epoxy resin system undergoes physical changes such as gelation and vitrification before complete solidification [15, $24,27]$. Gel time is very critical in polymer processing and depends on numerous factors which include constituents of reactants, cure temperature, cure rate, and $\mathrm{pH}$ of the mixture $[13,23]$. In the current study, gel point for each composition 
was determined as the crossover point between storage and loss moduli and the results are summarized in Table 2. At onset of experiment, viscosity of each composition was low with higher values of loss moduli due to the dominance of viscous properties of SC-15 epoxy resins. However, with progression of chemical reaction, viscosity increased rapidly passing gel point at different times based on stoichiometric composition and curing temperature. Various gelation time reported in each system was not only indicative of influence of surface modifications but also manifests comparative catalytic behavior among nanoclay-infused samples during curing. For example, gelation occurred sooner in Cloisite modified SC-15 samples compared to Nanomer modified samples at all temperatures considered in this study. This behavior was attributed to better interactions between organic modifiers used in Cloisite nanoclays and SC-15 molecules leading to increased nanoclay participating in the chemical reaction during curing. It also leads to increased rate of chemical reaction and demonstrates an active interaction between exposed surface of nanoclay particles and epoxy molecules within the percolated pseudosolid-like structure during curing $[14,21,24]$. On the other hand, Nanomer infused samples had longer gel time, indicating a relatively less interaction between SC-15 epoxy molecules and quaternary trimethyl stearyl ammonium salts used in modification of clay. For nanoclay based systems, there was an enhanced reaction when compared to neat samples at the same temperature. Temperature has also been shown to influence viscosity, vitrification, and degree of intergallery expansion of clay platelets, thereby affecting chemical reaction during curing [16-18].

Viscoelastic properties at various curing temperatures were observed to decrease with increasing temperature. For example, gelation time and corresponding storage modulus at gel points decreased across the board as curing temperature increased. Maximum storage modulus at gel point was attained at $60^{\circ} \mathrm{C}$ for all samples, and the values were higher in all nanophased samples. Among the nanocomposites, Nanomer I.28E infused samples yielded the highest value of storage modulus. For samples cured at $70^{\circ} \mathrm{C}$, neat system had the highest modulus at gel point and among the nanoclay infused SC-15; samples with Cloisite 30B had the highest values. However, at curing temperature of $80^{\circ} \mathrm{C}$, samples with Cloisite $10 \mathrm{~A}$ showed the highest values in storage modulus at gel point. This behavior leads to the speculation that optimization of material properties in nanoclay infused composites can be achieved when cured at temperatures lower than $70^{\circ} \mathrm{C}$. Thus, a significant drop in storage modulus and viscosity at gel point observed among nanocomposites samples cured at 60 and $70^{\circ} \mathrm{C}$ attests to this conclusion.

According to Flory's (1953) gelation theory, degree of cure at gel time $\left(\alpha_{\text {gel }}\right)$ of any polymer system depends on the chemical structure and functionalities of that system and considered constant regardless of the cure temperature. Therefore integrating (4) with limits from of 0 to gel time $\left(t_{\text {gel }}\right)$ and taking natural logarithm of both sides, a relation can be established from the plots of $\ln \left(t_{\text {gel }}\right)$ versus absolute temperature $(T)$, where the slope of curve gives the apparent

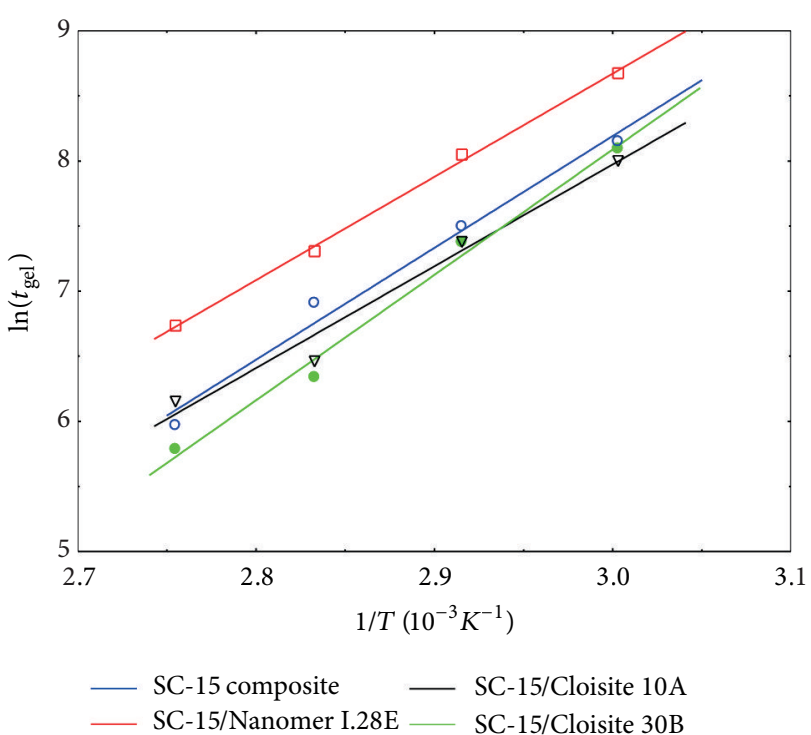

Figure 5: Plots of $\ln \left(t_{\text {gel }}\right)$ versus inverse absolute temperature (T) during isothermal rheological studies.

activation energy of cure reaction. The relationship can be expressed as

$$
\begin{gathered}
t_{\mathrm{gel}}=\frac{1}{K(T)} \cdot \int_{0}^{\alpha_{\mathrm{gel}}} \frac{1}{f(\alpha)} d \alpha, \\
\ln \left(t_{\mathrm{gel}}\right)=\ln \left[\frac{1}{A_{0}}\left(\int_{0}^{\alpha_{\mathrm{gel}}} \frac{1}{f(\alpha)} d \alpha\right)\right]+\frac{E_{a}}{R} \cdot \frac{1}{T},
\end{gathered}
$$

where $A_{0}$ is preexponential factor at $t=0$, and $\alpha_{\text {gel }}$ is the conversion at gel point.

Figure 5 shows experimental data plots of $\ln \left(t_{\text {gel }}\right)$ versus absolute temperature $(T)$ where apparent activation energy determined from the linear fit curve was 69.59, 65.93, 65.03, and $80.06 \mathrm{KJ} / \mathrm{mol}$ for neat SC-15, Nanomer I.28E, and Cloisite $10 \mathrm{~A}$ and 30B infused SC-15 epoxy system, respectively.

\subsection{DSC Characterization}

3.3.1. Dynamic DSC Studies. Representative DSC thermograms obtained from dynamic scans of unmodified and modified SC- 15 at heating rates of 2.5 and $10^{\circ} \mathrm{C} / \mathrm{min}$ are shown in Figure 6. Results from DSC scans showed a single exothermic peak throughout the curing process for all samples, an indication that presence of different MMT did not affect reaction mechanism. At lower heating rates, onset of chemical reactions and reaction rates were slow due to lower viscosity and less molecular mobility of reactants, while higher heating rates offered less time and increased reaction rate for each system. As a result, exothermic peak temperature $\left(T_{p}\right)$ shifted to higher temperatures with increasing ramp rate to compensate for insufficient reaction time. Also, higher heating rates provided enough momentum to the system thereby increasing mobility and collisions between epoxy molecules, resulting in higher enthalpy at the end of each scan. Summary 


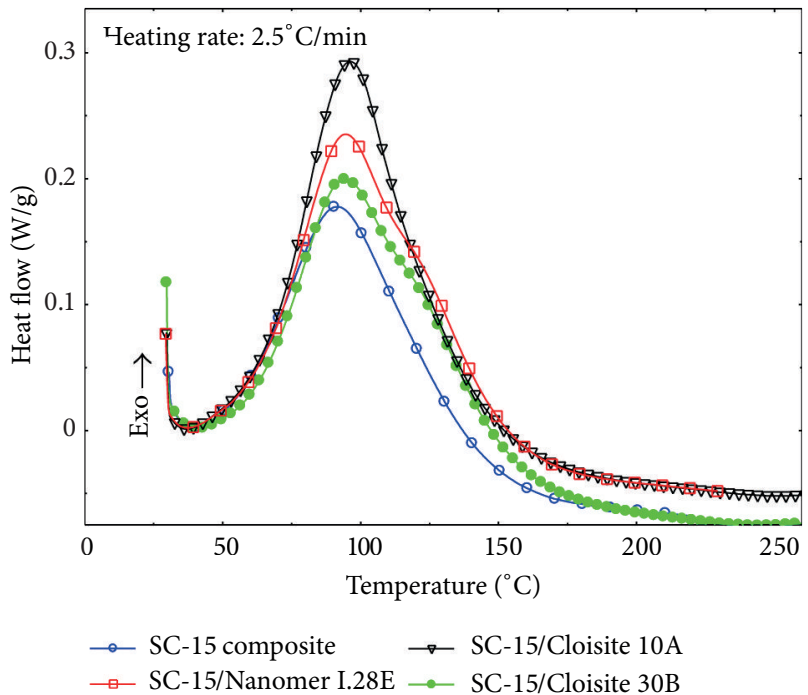

(a)

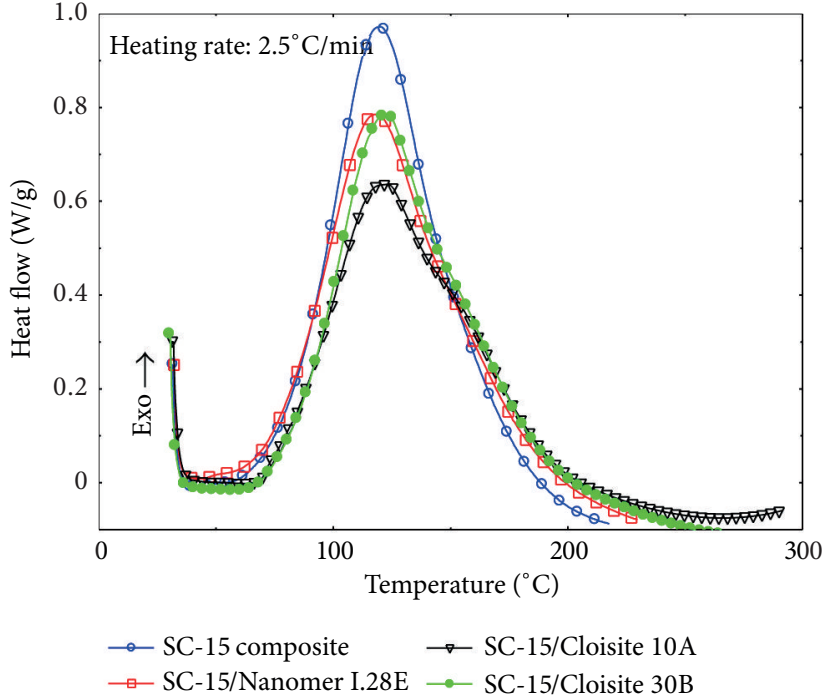

(b)

FIGURE 6: DSC thermograms of neat SC15 and SC15 modified with Nanomer I.28E and Cloisite 10A and Cloisite 30B at (a) 2.5 and (b) heating rate: $10^{\circ} \mathrm{C} / \mathrm{min}$.

TABLE 3: Results of dynamic DSC scan.

\begin{tabular}{|c|c|c|c|c|c|c|c|}
\hline \multirow{2}{*}{ Epoxy system } & \multirow{2}{*}{ Scanning rate, $\mathrm{C} / \mathrm{min}$} & \multicolumn{6}{|c|}{ Kinetic parameter } \\
\hline & & $T_{i},{ }^{\circ} \mathrm{C}$ & $T_{p},{ }^{\circ} \mathrm{C}$ & $T_{f},{ }^{\circ} \mathrm{C}$ & $\Delta H, \mathrm{~J} / \mathrm{g}$ & $E_{a}, \mathrm{KJ} / \mathrm{mol}$ & $\ln A, 1 / \mathrm{min}$ \\
\hline \multirow{4}{*}{ SC-15 } & 2.5 & 55.16 & 93.47 & 219.07 & \multirow{4}{*}{$315.80 \pm 20.86$} & \multirow{4}{*}{$49.10 \pm 5.89$} & \multirow{4}{*}{$6.12 \pm 0.85$} \\
\hline & 5.0 & 65.40 & 107.33 & 218.16 & & & \\
\hline & 10.0 & 78.98 & 119.67 & 216.57 & & & \\
\hline & 15.0 & 94.41 & 133.64 & 218.40 & & & \\
\hline \multirow{4}{*}{ SC-15/Nanomer I.28E } & 2.5 & 61.31 & 96.16 & 241.46 & \multirow{4}{*}{$357.60 \pm 13.91$} & \multirow{4}{*}{$61.90 \pm 6.39$} & \multirow{4}{*}{$7.96 \pm 0.90$} \\
\hline & 5.0 & 66.99 & 106.43 & 218.19 & & & \\
\hline & 10.0 & 79.78 & 120.78 & 269.25 & & & \\
\hline & 15.0 & 87.11 & 129.70 & 277.40 & & & \\
\hline \multirow{4}{*}{ SC-15/Cloisite 10A } & 2.5 & 63.41 & 97.34 & 252.37 & \multirow{4}{*}{$341.30 \pm 24.16$} & \multirow{4}{*}{$57.30 \pm 6.02$} & \multirow{4}{*}{$7.26 \pm 0.81$} \\
\hline & 5.0 & 70.92 & 110.64 & 261.54 & & & \\
\hline & 10.0 & 76.77 & 122.26 & 265.50 & & & \\
\hline & 15.0 & 92.03 & 134.29 & 282.80 & & & \\
\hline \multirow{4}{*}{ SC-15/Cloisite 30B } & 2.5 & 61.40 & 94.49 & 242.94 & \multirow{4}{*}{$354.60 \pm 13.55$} & \multirow{4}{*}{$58.00 \pm 1.39$} & \multirow{4}{*}{$7.30 \pm 0.19$} \\
\hline & 5.0 & 69.30 & 110.51 & 276.19 & & & \\
\hline & 10.0 & 82.27 & 123.85 & 291.92 & & & \\
\hline & 15.0 & 96.27 & 134.12 & 291.82 & & & \\
\hline
\end{tabular}

of dynamic scans for all samples are presented in Table 3, where influence of clay surface modifications on kinetic parameters can be observed. There were slight changes in onset of reaction temperature $\left(T_{i}\right)$ between neat and the various MMT infused samples as can be seen in Table 3 . However, final reaction temperature $\left(T_{f}\right)$ significantly increased with the addition of MMT at various heating rates, along with enthalpy $(\Delta H)$ and activation energy of reaction. Apparent activation energy of reaction for each system (Table 3 ) was calculated using TA Instruments' Specialty Library based on ASTM E698 utilizing Ozawa (1964) method [19]. This approach required at least three or more scans at different heating rates; hence, different heating rates were employed in the current study.

Overall heat of reaction $(\Delta H)$ and activation energy $\left(E_{a}\right)$ of reaction for all nanocomposites were higher compared to neat. Nanomer I.28E infused samples showed the highest values, with about 13 and 26\% increase when compared to neat respectively. Observed high enthalpy for Nanomer I.28E infused samples may be due to lower viscosity and relatively less percolation of epoxy molecules into clay layers; hence, more heat was required to initiate polymerization and crosslinking, leading to higher enthalpy of reaction. On the other hand, samples with Cloisite 10A showed lower enthalpy 
TABLE 4: Summary of isothermal DSC scans.

\begin{tabular}{|c|c|c|c|c|c|c|}
\hline \multirow{2}{*}{ Samples } & \multirow{2}{*}{ Isothermal temperature, ${ }^{\circ} \mathrm{C}$} & \multicolumn{5}{|c|}{ Kinetic parameters } \\
\hline & & $n$ & $m\left(\times 10^{-2}\right)$ & $K\left(\times 10^{-3}\right)$ & $T_{p}, \min$ & $\Delta H, \mathrm{~J} / \mathrm{g}$ \\
\hline \multirow{4}{*}{ SC-15 epoxy composite } & 60 & $1.15 \pm 0.053$ & $31.1 \pm 2.9$ & $24.0 \pm 2.0$ & 32.53 & 301.10 \\
\hline & 70 & $1.66 \pm 0.096$ & $26.0 \pm 5.2$ & $33.0 \pm 4.0$ & 19.93 & 444.04 \\
\hline & 80 & $1.72 \pm 0.065$ & $29.8 \pm 3.5$ & $73.0 \pm 6.0$ & 13.37 & 351.36 \\
\hline & 90 & $2.44 \pm 0.12$ & $30.8 \pm 6.8$ & $94.0 \pm 14.0$ & 12.70 & 429.27 \\
\hline \multirow{4}{*}{$\begin{array}{l}\text { SC-15/Nanomer I.28E } \\
\text { epoxy nanocomposite }\end{array}$} & 60 & $1.61 \pm 0.05$ & $23.2 \pm 3.0$ & $33.0 \pm 2.0$ & 15.85 & 442.54 \\
\hline & 70 & $1.70 \pm 0.12$ & $3.6 \pm 0.1$ & $28.1 \pm 4.0$ & 10.60 & 460.68 \\
\hline & 80 & $2.09 \pm 0.10$ & $1.6 \pm 0.1$ & $62.0 \pm 7.0$ & 9.70 & 473.95 \\
\hline & 90 & $2.70 \pm 0.08$ & $28.1 \pm 4.5$ & $127.0 \pm 12.0$ & 9.82 & 511.97 \\
\hline \multirow{4}{*}{$\begin{array}{l}\text { SC-15/Cloisite 10A epoxy } \\
\text { nanocomposite }\end{array}$} & 60 & $1.22 \pm 0.034$ & $15.0 \pm 1.8$ & $24.6 \pm 1.0$ & 20.87 & 946.83 \\
\hline & 70 & $1.34 \pm 0.037$ & $8.9 \pm 0.2$ & $37.4 \pm 2.0$ & 9.87 & 1079.58 \\
\hline & 80 & $1.31 \pm 0.069$ & $3.8 \pm 0.5$ & $48.0 \pm 4.0$ & 7.47 & 995.57 \\
\hline & 90 & $1.37 \pm 0.086$ & $3.8 \pm 4.7$ & $58.0 \pm 6.0$ & 7.50 & 1063.06 \\
\hline \multirow{4}{*}{$\begin{array}{l}\text { SC-15/Cloisite 30B epoxy } \\
\text { nanocomposite }\end{array}$} & 60 & $1.43 \pm 0.059$ & $30.0 \pm 1.0$ & $38.0 \pm 3.0$ & 15.41 & 1287.33 \\
\hline & 70 & $1.15 \pm 0.054$ & $5.8 \pm 0.3$ & $22.7 \pm 1.0$ & 7.55 & 1331.49 \\
\hline & 80 & $1.73 \pm 0.120$ & $3.3 \pm 0.7$ & $54.1 \pm 8.0$ & 7.47 & 833.51 \\
\hline & 90 & $1.83 \pm 0.150$ & $0.6 \pm 0.0$ & $55.8 \pm 10.0$ & 8.15 & 1127.29 \\
\hline
\end{tabular}

and activation energy of reactions among MMT infused samples.

From these results, it can also be seen that each infused MMT system required different amount of energy to overcome energy barrier to fuse reacting species together compared to neat. It also establishes the influence of different surfactants used in clay modification on overall reaction kinetics including activation energy. Among MMT infused samples, Cloisite 10A had relatively lower activation energy, while Nanomer I.28E had the highest value. These results corroborate results from rheological and XRD studies. These values when compared with neat system constitute an increase of approximately 17 and $26 \%$ for Cloisite $10 \mathrm{~A}$ and Nanomer I.28E infused samples respectively.

3.3.2. Isothermal DSC Studies. Advantages of isothermal DSC technique include elimination of thermal gradient effects, errors due to nonlinear heating ramps, and minimizing decomposition interferences of sample. Curing of epoxy amine system is shown to be autocatalytic in nature [2629 ] where the cure rate $d \alpha / d t$ and degree of cure, $\alpha$ can be expressed according to Kamal's model as follows:

$$
\frac{d \alpha}{d t}=\left(k_{1}+k_{2} \alpha^{m}\right)(1-\alpha)^{n}
$$

where $m$ and $n$ are the reaction orders, $k_{1}$ and $k_{2}$ are the reaction rate constants, where $k_{1}$ is the kinetic rate constant corresponding to noncatalytic reaction between epoxide and amine groups, and $k_{2}$ is the rate constant due to hydroxyl group formed as a result of catalytic effect of amine curing agent. Constant $k_{1}$ can be determined based on the initial rate $\alpha=0 . k_{1}$ and $k_{2}$ are assumed to have an Arrhenius relationship; that is,

$$
\begin{aligned}
& k_{1}=A_{1} e^{\left(E_{a 1} / R T\right)}, \\
& k_{2}=A_{2} e^{\left(E_{a 2} / R T\right)} .
\end{aligned}
$$

However, TA Instruments "Specialty Library" considers overall $k$ for each reaction set during analyses and therefore reported rate constant values $(k)$ are that of overall value for each composition.

Representative isothermal DSC thermograms obtained for unmodified and Cloisite 10A infused SC-15 epoxy systems at $60,70,80$, and $90^{\circ} \mathrm{C}$ are shown in Figures $7(\mathrm{a})$ and 7 (b), with characteristic autocatalytic thermogram. During isothermal curing, rate of chemical reaction increased with time and each reaction went through a maximum reaction peak before retarding due to gelation and vitrification. With increasing isothermal cure temperature, reaction rate increased and intensity of reaction peaked at a relatively shorter time regardless of the composition. Heat of reaction $(\Delta H)$ from isothermal scans also showed higher values for MMT infused systems compared to neat as shown in Table 4. This corroborates results from dynamic scans for all nanophased compositions compared to neat (Table 3 ). These results also showed a dependency of kinetic parameter $n$ on reaction temperatures and surface modifications of clay. As reaction temperature increased, reaction order $n$ increased and among various MMT infused samples; Cloisite 10A samples had the least values. While no particular trend was observed in the values of $m$, it however confirms complexities involved in epoxy curing.

Studies $[27,28]$ have shown that for autocatalytic epoxy curing overall reaction order $(n+m)$ is assumed to be 2 . Using "Specialty Library" software, reaction temperatures at various 


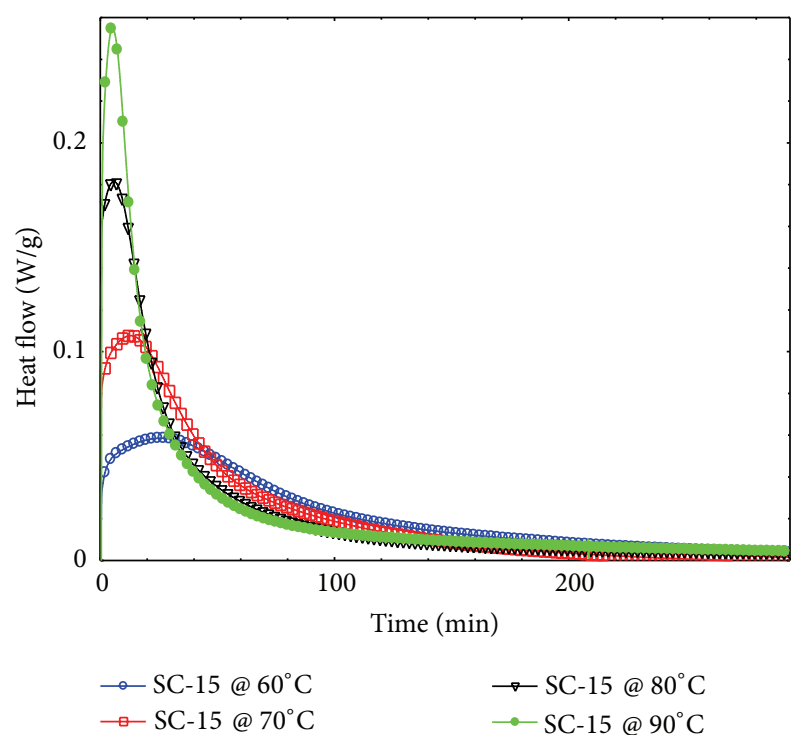

(a)

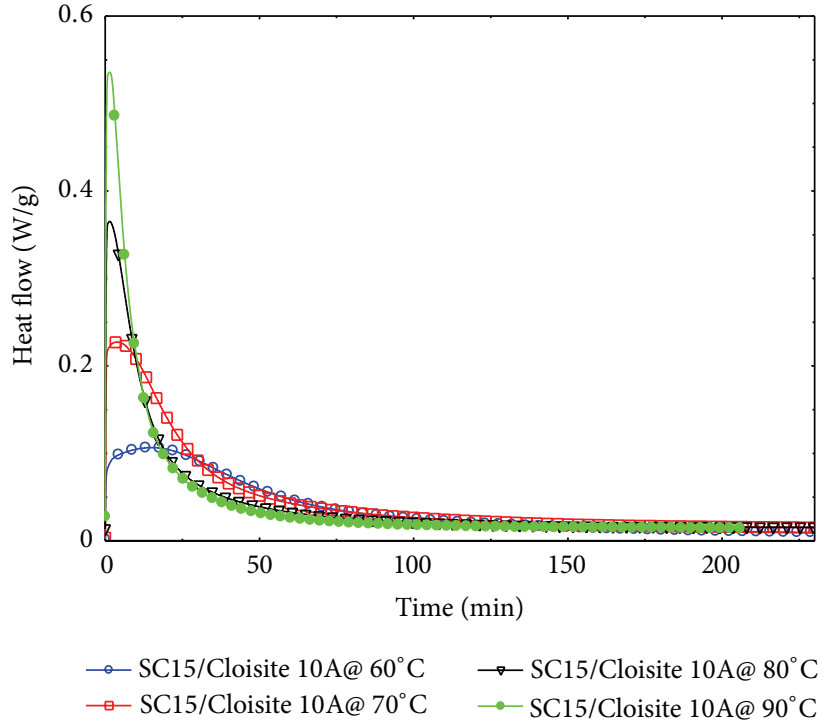

(b)

Figure 7: Representative isothermal heat flow thermogram for (a) neat and (b) Cloisite 10A infused SC-15 epoxy at different curing temperatures.

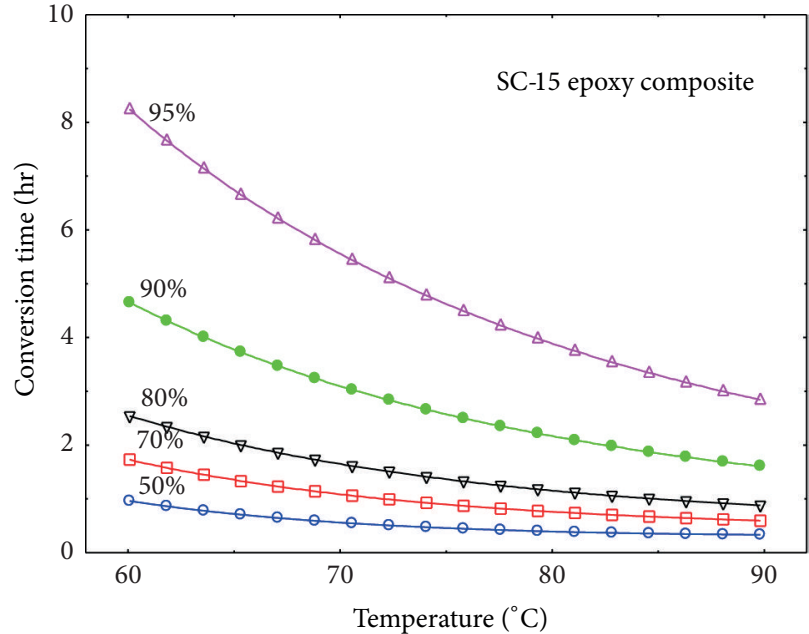

(a)

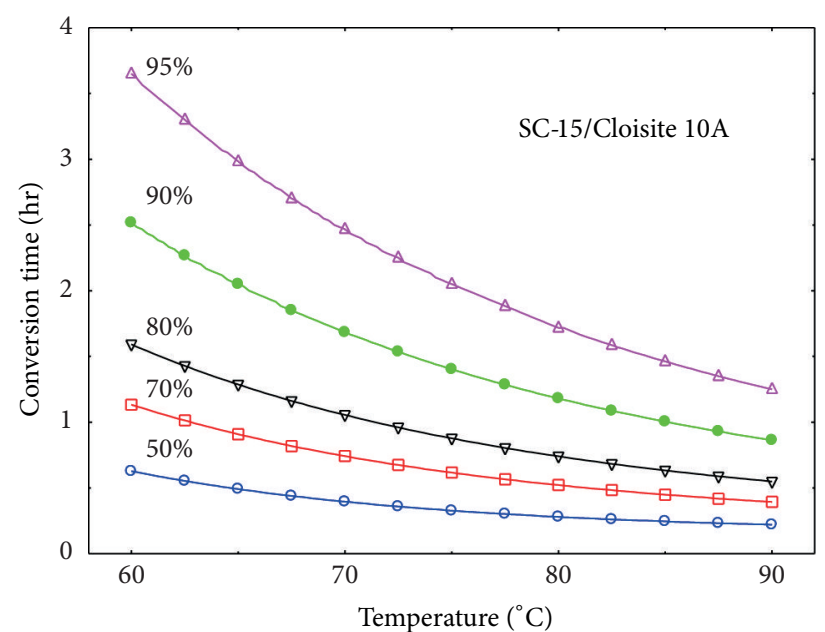

(b)

FIGURE 8: Conversion time-temperature curves of (a) neat SC-15 and (b) SC-15 with Cloisite 10A.

conversion times were generated for all samples including neat and plotted as shown in Figure 8. Using this set of curves and reaction orders obtained from each scan presented in Table 4, corresponding temperature for the closest reaction order $(n+m)$ of approximately 2 is as follows: for neat system $(0 \mathrm{wt} . \%)$, reaction temperature would be $80^{\circ} \mathrm{C}$, for Nanomer I.28E, it is $70^{\circ} \mathrm{C}$, and, for Cloisite $10 \mathrm{~A}$ and $30 \mathrm{~B}$, it is $60^{\circ} \mathrm{C}$. It follows that required curing temperature for optimization of epoxy composite properties was influenced by the presence of different constituents. Influence of these constituents are dictated by their surface chemistry; hence, the effect of different clay surface modifications can affect ultimate properties of final nanocomposites. In our previous studies [30], it was shown that surface modifications of these MMT nanoclays influenced viscoelastic properties and activation energy of decomposition of epoxy composites during thermal stability studies. Furthermore, the study showed that different surface modification of MMT influenced the rate of chemical degradation caused by UV radiation exposure. These observations can be attributed to chemical interaction between MMT clay particles and epoxy molecules during curing as observed in rheological studies. Influence of different surface modification of montmorillonite nanoclay on cure behavior was also apparent based on results from each curing temperature, showing different cure times for each sample. 


\section{Conclusion}

Influence of different surface modifications on rheological and cure behavior was studied using SC-15 epoxy resin modified with Nanomer I.28E and Cloisite $10 \mathrm{~A}$ and $30 \mathrm{~B}$ montmorillonite nanoclays. Presence of different surface modifications of MMT had no effect on the cure reaction mechanism; however, viscosity and subsequent heat of reaction and activation energy of reaction were significantly affected. Surface modifications of montmorillonite nanoclay also affected gelation time leading to different cure time at various cure temperatures. These parameters influence overall properties; hence, for any modified epoxy resin system with MMT cure kinetic studies are essential in order to optimize the processing parameters to obtain desirable properties of final composites. Also, temperature and time required to cure MMT modified SC-15 may differ based on surface modification of MMT.

\section{Acknowledgments}

The authors would like to acknowledge Alabama Commission on Higher Education (ACHE), Office of Naval Research (ONR), and National Science Foundation (NSF-EPSCoR) for their financial support. The authors have no affiliation and no commercial interests with any of the manufacturers of all commercially available products used in this study.

\section{References}

[1] F. Hussain, M. Hojjati, M. Okamoto, and R. E. Gorga, "Review article: polymer-matrix nanocomposites, processing, manufacturing, and application: an overview," Journal of Composite Materials, vol. 40, no. 17, pp. 1511-1575, 2006.

[2] P. H. C. Camargo, K. G. Satyanarayana, and F. Wypych, "Nanocomposites: synthesis, structure, properties and new application opportunities," Materials Research, vol. 12, no. 1, pp. 1-39, 2009.

[3] M. Alexandre and P. Dubois, "Polymer-layered silicate nanocomposites: preparation, properties and uses of a new class of materials," Materials Science and Engineering R, vol. 28, no. 1-2, pp. 1-63, 2000.

[4] X. Kornmann, M. Rees, Y. Thomann, A. Necola, M. Barbezat, and R. Thomann, "Epoxy-layered silicate nanocomposites as matrix in glass fibre-reinforced composites," Composites Science and Technology, vol. 65, no. 14, pp. 2259-2268, 2005.

[5] E. Bozkurt, M. Tanoglu, and E. Kaya, "Mechanical and thermal behavior of non-crimp glass fiber reinforced layered clay/epoxy nanocomposites," Composites Science and Technology, vol. 67, no. 15-16, pp. 3394-3403, 2007.

[6] P. I. Xidas and K. S. Triantafyllidis, "Effect of the type of alkylammonium ion clay modifier on the structure and ther$\mathrm{mal} /$ mechanical properties of glassy and rubbery epoxy-clay nanocomposites," European Polymer Journal, vol. 46, no. 3, pp. 404-417, 2010.

[7] E. Manias, G. Polizos, H. Nakajima, and M. J. Heidecker, "Fundamentals of polymer nanocomposite technology," in Flame Retardant Polymer Nanocomposites, Wiley, Hoboken, NJ, USA, 2007.
[8] P. Kiliaris and C. D. Papaspyrides, "Polymer/layered silicate (clay) nanocomposites: an overview of flame retardancy," Progress in Polymer Science, vol. 35, no. 7, pp. 902-958, 2010.

[9] L. Le Pluart, J. Duchet, H. Sautereau, P. Halley, and J.-F. Gerard, "Rheological properties of organoclay suspensions in epoxy network precursors," Applied Clay Science, vol. 25, no. 3-4, pp. 207-219, 2004.

[10] A. Yousefi, G. Lafleur, and R. Gauvin, "Kinetic studies of thermoset cure reactions: a review," Polymer Composites, vol. 18, no. 2, pp. 157-168, 1997.

[11] T. P. Mohan, R. Velmurugan, and M. R. Kumar, "Rheology and curing characteristics of epoxy-clay nanocomposites," Polymer International, vol. 54, no. 12, pp. 1653-1659, 2005.

[12] D. W. Litchfield and D. G. Baird, "The rheology of high aspect ratio nanoparticle filled liquids," The British Society of Rheology, pp. 1-60, 2006.

[13] S. S. Ray and M. Okamoto, "Polymer/layered silicate nanocomposites: a review from preparation to processing," Progress in Polymer Science, vol. 28, no. 11, pp. 1539-1641, 2003.

[14] K. Beazley, "Industrial aqueous suspensions," in Rheometry: Industrial Applications, Research Studies Press, England, UK, 1980.

[15] J. Ren, B. F. Casanueva, C. A. Mitchell, and R. Krishnamoorti, "Disorientation kinetics of aligned polymer layered silicate nanocomposites," Macromolecules, vol. 36, no. 11, pp. 4188-4194, 2003.

[16] S. Montserrat and J. G. Martín, "Non-isothermal curing of a diepoxide-cycloaliphatic diamine system by temperature modulated differential scanning calorimetry," Thermochimica Acta, vol. 388, no. 1-2, pp. 343-354, 2002.

[17] H. Cai, P. Li, G. Sui et al., "Curing kinetics study of epoxy resin/flexible amine toughness systems by dynamic and isothermal DSC," Thermochimica Acta, vol. 473, no. 1-2, pp. 101-105, 2008.

[18] Z. Wang and T. J. Pinnavaia, "Intercalation of poly(propyleneoxide) amines (Jeffamines) in synthetic layered silicas derived from ilerite, magadiite, and kenyaite," Journal of Materials Chemistry, vol. 13, pp. 2127-2131, 2003.

[19] ASTM, E698 Standard Test Method for Arrhenius Kinetic Constants for Thermally Unstable Materials, American Society of Testing and Materials, West Conshohocken, Pa, USA, 2005.

[20] D. Dean, R. Walker, M. Theodore, E. Hampton, and E. Nyairo, "Chemorheology and properties of epoxy/layered silicate nanocomposites," Polymer, vol. 46, no. 9, pp. 3014-3021, 2005.

[21] T. B. Tolle and D. P. Anderson, "The role of preconditioning on morphology development in layered silicate thermoset nanocomposites," Journal of Applied Polymer Science, vol. 91, no. 1, pp. 89-100, 2003.

[22] R. Krishnamoorti, J. Ren, and A. S. Silva, "Shear response of layered silicate nanocomposites," Journal of Chemical Physics, vol. 114, no. 11, pp. 4968-4973, 2001.

[23] Y. Jung, Y.-H. Son, J.-K. Lee, T. X. Phuoc, Y. Soong, and M. K. Chyu, "Rheological behavior of clay-nanoparticle hybridadded bentonite suspensions: specific role of hybrid additives on the gelation of clay-based fluids," ACS Applied Materials and Interfaces, vol. 3, no. 9, pp. 3515-3522, 2011.

[24] P. Pustkova, J. M. Hutchinson, F. Roman, and S. Montserrat, "Homopolymerization effects in polymer layered silicate nanocomposites based upon epoxy resin: implications for exfoliation," Journal of Applied Polymer Science, vol. 114, no. 2, pp. 1040-1047, 2009. 
[25] Y.-N. Chan, T.-Y. Juang, Y.-L. Liao, S. A. Dai, and J.-J. Lin, "Preparation of clay/epoxy nanocomposites by layered-doublehydroxide initiated self-polymerization," Polymer, vol. 49, no. 22, pp. 4796-4801, 2008.

[26] F. Bensadoun, N. Kchit, C. Billotte, F. Trochu, and E. Ruiz, "A comparative study of dispersion techniques for nanocomposite made with nanoclays and an unsaturated polyester resin," Journal of Nanomaterials, vol. 2011, Article ID 406087, 12 pages, 2011.

[27] K. Horie, H. Hiura, M. Sawada, and H. Kambe, "Calorimetric investigation of polymerization reactions. III. curing reaction of epoxides with amines," Journal of Polymer Science A-1, vol. 8, no. 6, pp. 1357-1372, 1970.

[28] S. Sourour and M. R. Kamal, "Differential scanning calorimetry of epoxy cure: isothermal cure kinetics," Thermochimica Acta, vol. 14, no. 1-2, pp. 41-59, 1976.

[29] T. Ozawa, "Kinetic analysis of derivative curves in thermal analysis," Journal of Thermal Analysis, vol. 2, no. 3, pp. 301-324, 1970.

[30] A. Tcherbi-Narteh, M. Hosur, E. Triggs, and S. Jeelani, “Thermal stability and degradation of diglycidyl ether of bisphenol A epoxy modified with different nanoclays exposed to UV radiation," Polymer Degradation and Stability, vol. 98, no. 3, pp. 759770, 2013. 

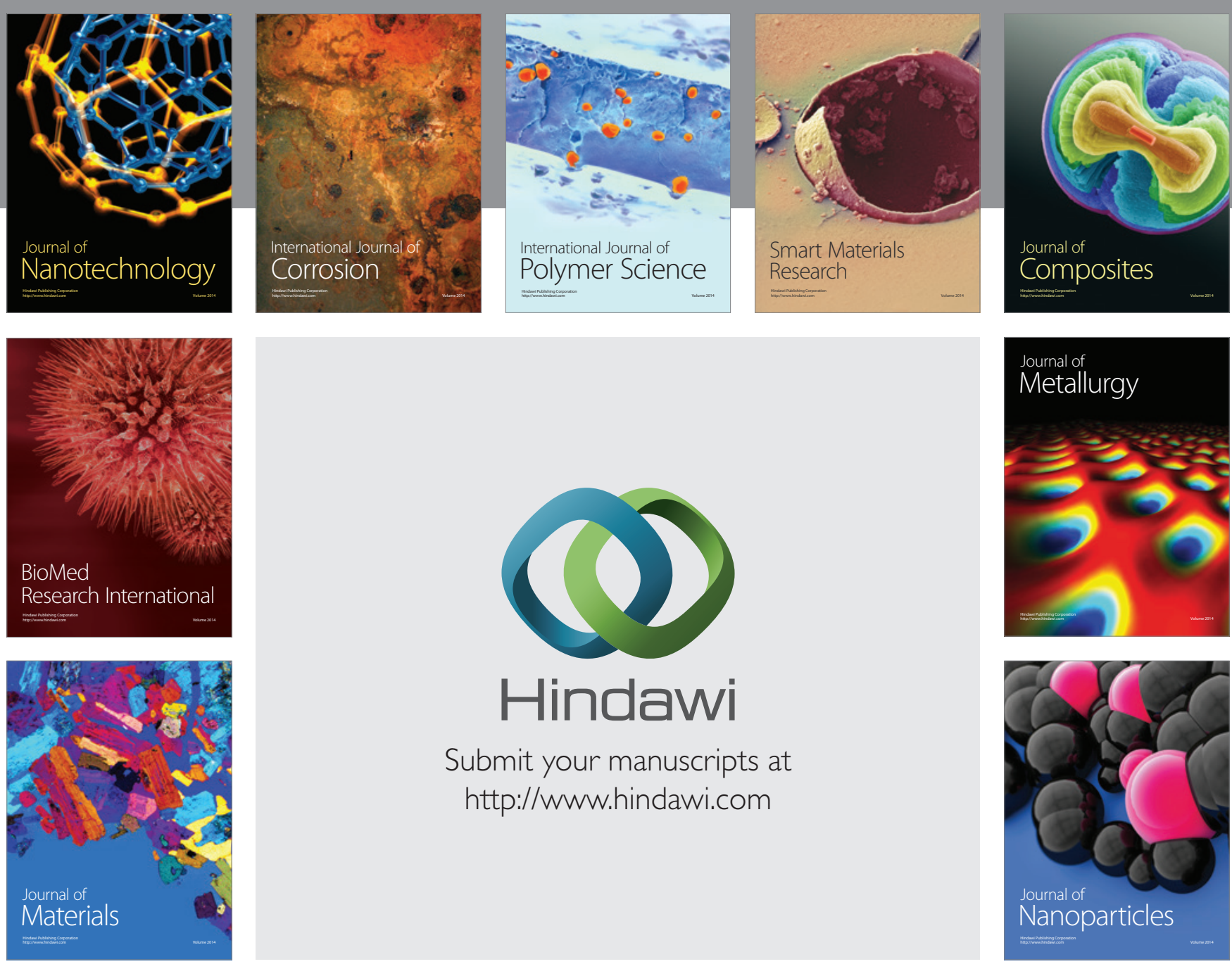

Submit your manuscripts at http://www.hindawi.com
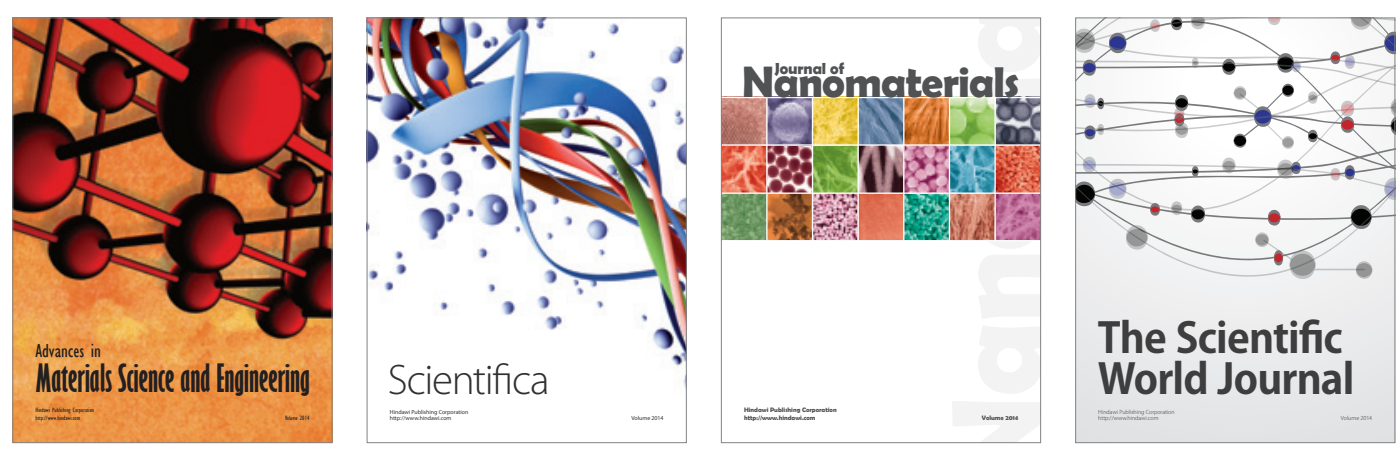

\section{The Scientific World Journal}
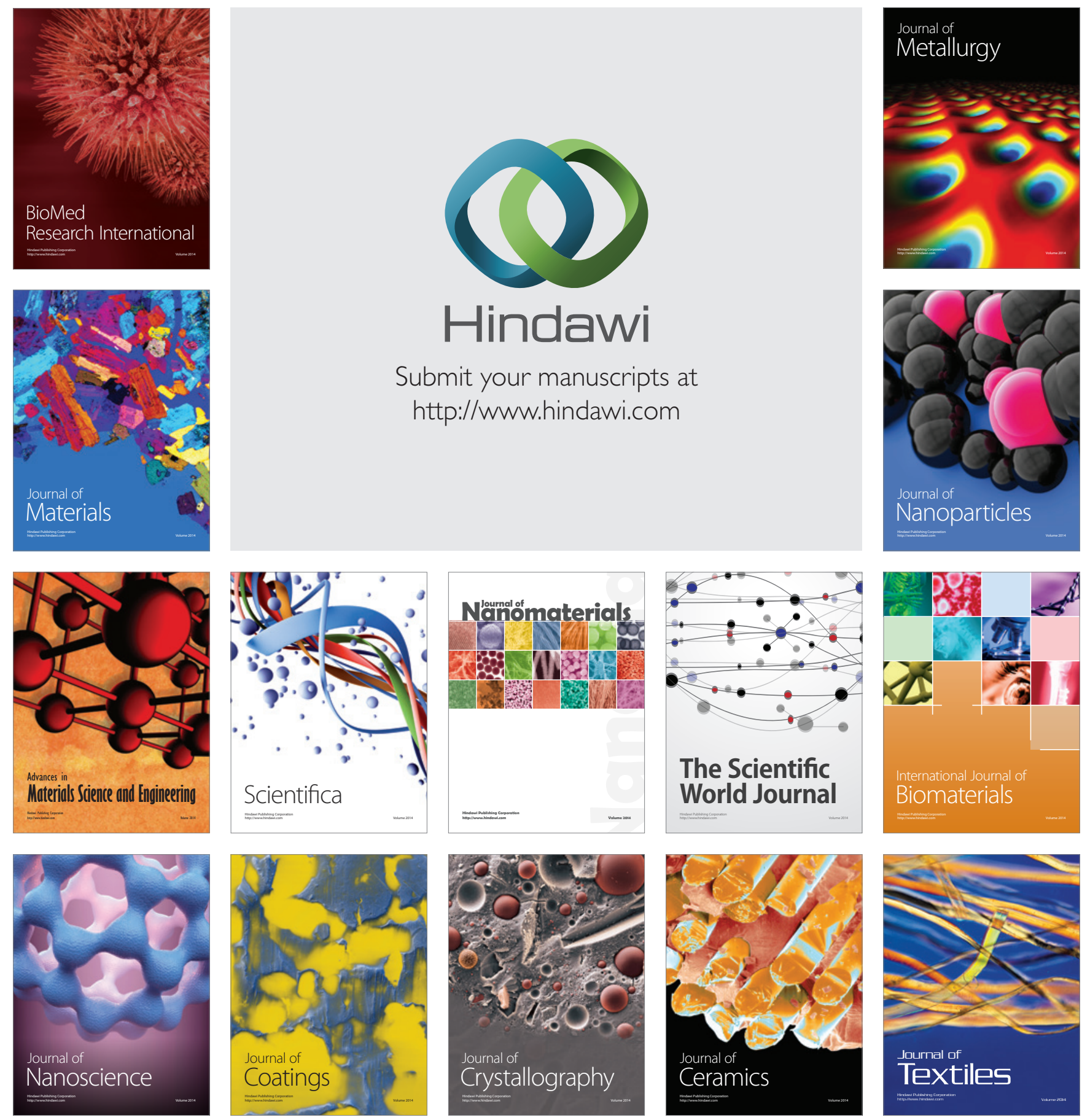